\title{
RESPONSIBLE MANAGEMENT OF ONLINE ACADEMIC REPUTATIONS
}

\author{
SHARYN MCDONALD
}

\begin{abstract}
Online professional persona creation in academia provides individuals and their employing institutions a range of positive reputational benefits. However, not all academics are equipped to keep pace with the speed and dynamism of the new media environment. This paper examines the challenges experienced by academics who are communicating with multiple audiences across several online platforms, some mandated by their institutions. Some academics are vulnerable to the negative consequences of heightened exposure and need additional protection and support. This paper outlines a set of recommendations that centres on the need for universities to accept greater social responsibility in managing this emerging issue.
\end{abstract}

\section{KEY WORDS}

Professional persona, Work-life balance, Responsibility, Academics, Social media, Online

\section{INTRODUCTION}

Universities assume two core roles in society: on the one hand, they are centres of knowledge production disseminating research across a variety of disciplines. On the other hand, universities are also centres of learning where pedagogy is a key function. To fulfil these dual objectives these institutions seek employees who can competently balance the demands of research and teaching while emulating the core values and missions of the institution.

According to Dorothy Smith, universities are organised by a mission that would have them "act as the critic and the conscience of society and for academics as scholarly citizens to foster intellectual insight, contribute to the struggle for justice, take up a level of social responsibility, be passionate about learning and be vocal of our times" (254). Implicit in this summary is the expectation that academic institutions and their academic employees should lead responsible practice. Universities may be well positioned to demonstrate best practice in social responsibility (Torrado, Bonilla and Clarke; Vallaeys; Wigmore-Álvarez and Ruiz-Lozano) but, as part of a holistic approach to social responsibility, universities should consider the needs of a key internal stakeholder-the academic.

While academia is often represented as a noble vocation, there are many pressures and expectations facing the academic that may remain unseen or un-detected to the outside observer. The tertiary landscape is constantly evolving and universities are described as complex, challenging, dynamic, and volatile (Pennington and Smith 434). For those employed in academic roles the constant need to keep pace with changing demands and expectations can be overwhelming. As a consequence, academics are attempting to perform those duties identified 
within position descriptions-research, teaching, and service-while trying to meet the hidden demands of the role-to engage in professional development and keep abreast of technological advancements (Weller). One area of concern is the expectation that academics will seamlessly and continually incorporate evolving social media into their research and pedagogy.

In the race for universities to seize opportunities and be seen to embrace technological advancements, academics have been caught up in what could be described as an uncontrolled work practice that is increasingly difficult to sustain. The weight of expectations in terms of research outputs and teaching quality is already a difficult combination to manage, particularly for academics trying to preserve an appropriate work-life balance (Weller). Maintaining a professional persona through social media further increases the pressure on these workers.

Undeniably, social media can be useful in developing a professional persona, yet there are several consequences that need to be examined. This paper begins by summarising the benefits of using social media to create a professional online persona. This is followed by a review of relevant literature to show that academic industry issue management has been inadequate over these matters, particularly with regard to personal well-being and the social responsibility universities should assume. It will conclude with recommendations for ways to ameliorate these conditions.

\section{SOCIAL MEDIA TOOLS AND THE BENEFITS OF INCREASED ONLINE VISIBILITY}

Social media can bring a host of reputational advantages to academics and the tertiary institutions that employ them. The tertiary education sector can include various forms of postsecondary education options, but this paper looks exclusively at universities and the unique expectations and prestige that emanate from such institutions. Universities are presented with an opportunity to use social media to assemble the outputs and best practices generated/demonstrated by academics and leverage this opportunity to curate "brand identity and marketing purposes" (Liebler and Chaney 399). Institutions have traditionally benefited from the visibility of their more prominent academics whose presence may carry influence and prestige (Barbour and Marshall). Prestigious academics are regarded as "public intellectuals" because they "write and speak" about their specialist knowledge to audiences beyond their professional colleagues (Lightman) and "become well-known to the general public for a willingness to comment on current affairs" ("Public intellectual"). Over time, this visible recognition has meant that public intellectuals are publicised in news or "representational media" including newspapers, magazines, radio, and television (Marshall, "Persona studies"). To cultivate a visible, vibrant public persona in academia, some academics are successfully combining traditional publications and speaking engagements with representational and new media. As Cassandra Atherton notes, with the functionality new media presents, public intellectuals have been able to further extend their conversations enabling active and accessible communication to online audiences:

The immediacy of the blog and social media and the way in which an online presence facilitates immediate communication between the public and the public intellectual through the posting of comments online, allows for a broad recognition of the intellectual in the public arena. (15)

This movement into the broader public arena is not solely reserved for the public intellectual. Experienced or novice academics can take advantage of the opportunities new media present to highlight their research and utilise social media platforms in order "to create and maintain a professional persona" (Liebler and Chaney 404). Online platforms and social media provide an increasing number of academics, regardless of discipline, the opportunity to communicate directly with both academic and non-academic publics. Academics seek to build bridges between their theoretical work and their practice (Boyer 16). Derek Barker views this "scholarship of engagement" as a way to communicate with public audiences in creative ways 
and "generate knowledge with public participation" (123). Academics have adopted a variety of new media to facilitate this exchange with multiple audiences.

Sidneyeve Matrix notes that there is an increase in academics across disciplines "venturing into the realms of social, mobile, and Web 2.0 technologies to experiment with digital tools for research and professionalization." Academics utilise a variety of social media tools and platforms including Facebook, LinkedIn, Academia.edu, Twitter, YouTube, Instagram, Pinterest, Skype, i-Tunes, webinars and blogs alongside internally available platforms such as Moodle or Blackboard (Barbour and Marshall; Liebler and Chaney; Matrix). Furthermore, Matrix acknowledges that social media adoption by academics is not linked to a specific generation: early career researchers through to senior professors are adopting new forms of media.

With the development of online platforms and repositories where individuals or collectives can take control of assembling and exhibiting structured content or media, there has been new emphasis on the role of "presentational media" (Marshall, "Persona studies") in tertiary institutions. It is now quite common to see a tabulation of publications, conferences, keynote speeches, and media coverage on the profile pages of an academic, particularly on the pages hosted by the institution that employs them. These profiles also commonly harbour additional information such as current research projects, teaching interests, and awards. In addition to such tangible outputs, academics have begun to incorporate new media with links to private blogs, LinkedIn profiles, Twitter feeds or web pages on their profile pages. Through adopting these various new media, academics have begun to take control of the "publicisation of the self" (Marshall, "Persona studies" 154) and to construct a persona (Marshall, "Personifying agency") representing their professional identity that not only promotes their identity and careers, but also differentiates them from other academics. The diverse forms of new media allow academics to promote forthcoming publications and public speaking engagements, expand and enhance networks, and diversify their teaching and approach to student engagement.

Student audiences have an interest in acquiring more and timely information from academics. An academic with teaching responsibilities may utilise new media to enhance his or her teaching and extend levels of engagement with students. While universities often provide some technical assistance for online courses and course components, some degree of digital competency is necessary for academics to teach through online learning platforms. Some academics have the technological capacity to excel in their use of online learning platforms and provide an engaging, innovative online learning experience. Teaching resources found on an online learning platform may include recorded video lectures, podcasts, and discussion boards supplemented with links to private blogs and a Twitter feed. As noted by Kim Barbour and P. David Marshall, some academics also use platforms such as Facebook and LinkedIn to facilitate staff/student dialogue. Academics can incorporate new media to diversify the learning experience, which subsequently presents student audiences with the opportunity to communicate in up-to-date discussions and participate in a more personalised, engaging experience.

Using social media allows an academic to communicate with audiences already engaged or invested in academic debate alongside those who were previously unaware. An example where academics are utilising new media to extend their reach is through the use of Twitter at conferences. Content dissemination is no longer limited to those physically present: Tweets extend the reach of content to current and potential new audiences. Twitter usage at conferences can generate interest in forthcoming conferences, and facilitates conversations during and after the present conference (Reinhardt et al.; Veletsianos). One advantage to the 140-character limitation (and other structural limits often embedded in micro-blogging) is that this condensed format can present content in a more palatable arrangement for broader audiences. David Smith supports the use of Twitter; he notes that it is "a way of engaging with communities who normally would not give 'academics' the time of day." In addition to reaching 
a wider audience, Twitter also bridges the gap between the time new work is produced and the time it is published which can take months or even years (Björk and Solomon) and alerts audiences to forthcoming research findings.

Given the considerable time spent preparing and refining academic papers for publication and the further delays in having work recognised or cited, sharing ideas through dedicated scholarly online forums has provided academics with a new platform for presenting the professional self. Academics are utilising social media platforms to engage with other academics, present scholarly information and bypass the traditional, highly competitive and restrictive peer-reviewed journal process (Barbour and Marshall). One online opportunity academics have begun to utilise is The Conversation, an online forum that provides "an independent source of news and views, sourced from the academic and research community and delivered direct to the public" (The Conversation). The Conversation targets an interdisciplinary academic audience and expands the reach of academic research at an accelerated pace. This platform has also become entwined with traditional media, for content generated through The Conversation "have also become an indispensable media resource: providing free content, ideas and talent to follow up for press, web, radio or TV" (The Conversation). Such a platform thus not only allows academics to move their research into the public sphere in a timely manner, but the comments function embedded in the site also facilitates timely feedback and a two-way dialogue between the author and audience.

The goal for academics may be a free-flow of information resulting in two-way dialogue or, as observed by Barbour and Marshall, some academics may choose to control their online persona utilising social media platforms to broadcast one-way. While some individuals are comfortable with the concept of the presentation of self via new media tools and online portfolios (Marshall, "Persona studies"), there are others that may harbour concerns or face barriers that prevent them from doing so. Barbour and Marshall raise the concern that those who do not take control of their own online academic persona by purposefully engaging with new media risk persona creation at the hands of others who may seek to "criticize or defame". This paper has acknowledged the benefits and rationale for taking control of one's own professional online persona and has illustrated how this is being achieved in universities, yet it is also important to explore the challenges and implications of social media use in academia. The next section explores the complexities and consequences and may help explain why some academics are reluctant to adopt new media to create an online professional persona.

\section{Challenges Involved in Maintaining an OnLine Professional Persona}

Taking control of the public discourse that surrounds an individual can be incredibly complex particularly when it involves various forms of communication media. As academic persona production moves from the regulated traditional measures of value, esteem, and inherent visibility publications attract (Barbour and Marshall), towards the complex navigation of external platforms, there are disadvantages and potential issues that can arise that are worth considering. Maintaining and monitoring an online professional persona requires time and the immediacy of social media can create undue pressure. Even individuals with a minimal online presence experience time management difficulties as they seek to address this multifaceted vocation.

With mounting pressures to keep pace with the evolving technologies and media used within and by universities, academics are at risk of extending their accessibility beyond personal limits. Matrix identifies several concerns including "accelerating expectations for faculty to be always on, connected, available to respond to email queries and provide instant feedback, 24/7" with the additional risk of a "loss of privacy and downtime," a compulsion to remain connected, and "pressure to keep up with the flow of information". Institutions mandate aspects such as the time is should take academics to respond to student emails and online posts, but care must be taken to ensure the replies are well-considered and within the 
various guidelines and policies that structure the professional's relationship to the student. In Deborah Lupton's research of 711 international academics and their use of social media she found,

Related to the problem of time pressure is the concern that academics may become obliged to use social media as yet another dimension of their work. Several people remarked that universities may be adding digital public engagement to the already long list of tasks demanded of their academic staff.

This increasing inability to manage an appropriate work-life balance has been highlighted in research conducted by Gail Kinman and Siobhan Wray. In their sample of over 24,000 higher education union members they found alarmingly high levels of stress and poor work-life balance, highlighting those "employed in teaching-and-research roles tended to report lower levels of well-being relating to demands, control and peer support, and higher levels of work-life conflict and stress, than those employed in teaching or research jobs" (33).

An individual's ability to cope was a concern that emerged from John Rowe's research. His article, "Student use of social media: when should the university intervene?," considers the perceived consequences an individual may face if an institution failed to provide support, and whether academics were labeled as overly sensitive to criticism. Rowe states:

What is considered harmful and damaging to one individual may be considered relatively trivial to another [...] Many staff indicated that they understood the need for students to vent and that they, as individuals, and the university should be 'big enough' to tolerate a fairly high level of criticism without intervening in any way. (251)

Criticism through social media is a challenge faced by academics, yet are these individuals prepared or equipped to cope with unexpected or unwarranted commentary (Barbour, Marshall and Moore), criticism, or publicity?

Social media adds another layer of critique to the traditional avenues embedded in academia. Traditional outputs produced by an academic are subject to challenge and critique by the academy (Dorothy Smith). Very few journals adopt an "open peer review" such as that used by the British Medical Journal (BM) wherein reviewers are identified and all reviewer comments are published with the completed research paper (BMJ). The common approach to the submission of research for publication is a system of blind peer review where reviewers are anonymous and feedback is private. Should academics receive negative criticism about their research, the private nature of the blind peer review process may allow an individual to seek appropriate support or guidance enabling them to cope with the feedback in a timely manner. Conversely, the visibility and immediacy of criticism via new media can form a public attack on the credibility of an academic's research or ideas. New media enables academics to extend twoway dialogue with new and existing audiences, but this also presents the risk of outright rejection of ideas and the potential for public ridicule.

In a public forum, the academic must be prepared to defend, reject, or ignore criticism. Many social media platforms have terms and conditions in place to generate respectful communication; academics are reliant on the enforcement of such rules to ensure offensive, illegal, or abusive posts are moderated and deleted. Yet even in forums such as The Conversation, the speed and vitriol of the critics may be overwhelming. Earlier this year Simon Chapman, a Professor of Public Health at University of Sydney, openly discussed in The Conversation his recent experience of trolls using social media platforms: "One troll actually went to the trouble of opening 16 different accounts, populating them with random followings and then firing off venom to me in his or her first tweet each time, hoping I wouldn't guess it was the same person" (Chapman). To help others in dealing with trolls, he converted his 
experience into a discussion piece. The first post received in response to Chapman's article was negative - the subsequent post duly pointed out this irony. Of the 65 comments relating to Chapman's article, approximately 25 were negative and critical of Simon Chapman, his research, or his article. Within these comments, some questioned Chapman's distinction between what constituted a "troll" or "trolling behaviour" as compared to simple disagreement. A further 12 posts were removed by the moderator. This illustrates the potential disadvantages of engaging in online platforms and how they can also compromise both the time and space for discussion of intellectual content. Sharing academic insights through such public forums can be turbulent, particularly for an under-prepared or self-conscious academic.

The link between academic freedom and institutional censorship has also been raised as a challenge to online public discourse (Gruzd, Staves, and Wilk). Some institutions have taken action against academics who have drawn negative attention to their employing university through their social media discourse. There are examples where academics have had their employment terminated for blog content deemed inappropriate (Horwedel), where they have been subjected to suspension for provocative Tweets (Thompson), overlooked for employment due to strongly worded Tweets (Thomason), and others have been threatened with legal action (Gruzd, Staves and Wilk). Academics engaging in both academic and non-academic public discussions through blogs and social media have some levels of control over the content they create, yet as has been demonstrated by public figures within other sectors such as politics, such comments can be readily taken out of context or misinterpreted. The emergence of censorship, whereby institutions are seen to distance themselves from reputational damage, presents a challenge to engaging in online public discussions and creates fears such as losing institutional or collegial support and jeopardising career opportunities (Gruzd, Staves and Wilk; Lupton). As Raizel Liebler and Keidra Chaney argue in "Here we are now, entertain us: Defining the line between personal and professional context on social media," social media policies are often more aligned with the interests of an organisation rather than those of the individual. Liebler and Chaney investigate the challenges surrounding the private/professional boundary from a legal perspective. They note that individuals engage in social media to connect with friends and families, yet there is a level of crossover when the same platforms are utilised in a professional environment. In this environment where the technology and usage patterns are continually evolving, it is important to re-evaluate existing regulations and draw from organisations exhibiting best practice (Liebler and Chaney). Barbour and Marshall reinforce the need for improved policy within universities and suggest a process of collaboration between academics and their employing institution to ensure an effective outcome for all.

The fluid nature of social media platforms has presented complexities for individuals attempting to cultivate and manage an online professional persona distinct from their private self. This blurred boundary between the private and professional self was a common concern raised in Deborah Lupton's research:

the most commonly raised concern for the respondents was that of privacy, and related to this, the blurring of boundaries between an individual's private life and her professional persona that takes place on social media. Respondents observed that it can be difficult to delimit and maintain these boundaries (22).

Academics that have adapted their technological skills and social media know-how from their private use of social media may find it difficult to retain information about the private self from information that represents the professional self, and information may inadvertently emerge from private networks or social spheres. For some, this may humanise the professional persona (David Smith), for others this may negatively affect their professional work persona. Academics must balance two-way dialogue with a variety of stakeholders and audiences, both internal and external: all have very specific needs and variable expectations.

The academic also faces the new challenge of persona production by others through external sites. Sites such as Rate my Professor or student-run forums that provide students with 
the opportunity to praise academics when they have experienced a positive teaching encounter or, conversely, vent if they feel begrudged. These sites provide students with the opportunity to discuss academics in a way that can shift the professional narrative from a persona assembled around research toward a student's perspective of their personal learning experience. There has been considerable debate about whether, and how, to monitor and manage this negative discourse and what constitutes inappropriate content. In John Rowe's study, he found that both students and staff generally agree that "threats of violence, racist and sexist comments, admissions of cheating or offers to cheat on academic work" should be followed up with a response by the institution (250). Some valid logistical difficulties are identified by Rowe such as the cost of actively monitoring social media sites and the potential consequences of overregulation, whereby students will post comments on "non-university student-run sites diluting the value of the feedback provided through formal mechanisms" (255). Rowe's argument was clear that institutions should take full responsibility for monitoring and regulating official university forums yet only respond to alerts or complaints raised about postings on external sites (255). Such a strategy leaves the academic exposed to unmonitored content that can have widespread reputational consequences if unchecked.

The enormity of the issue facing academics as they try to navigate, maintain, and problem solve their way through various communication platforms and scenarios should not be ignored nor understated. The benefits of using social media and online forums to assemble a professional persona are marred by a lack of control over content and the time-consuming nature of content creation, maintenance, monitoring, and continued engagement (Gruzd, Staves and Wilk; Lupton). A concurrent theme has emerged surrounding the well-being of the academic, drawing in factors of time management and the inability to personally manage externally created content. The next section acknowledges these challenges and provides some recommendations for further consideration.

\section{RECOMMENDATIONS FOR HIGHER EDUCATION INSTITUTIONS}

The development, maintenance, and monitoring of a professional persona has become an issue in need of management. Academics are not necessarily well equipped for dealing with issues that arise through engaging in social media and other online platforms mandated (or encouraged) by their institutions. If the institution responds by ignoring comments or, in extreme cases, condemns the academic for stating strong views, this communicates a strong message to those already engaged with new media as well as those yet to cross the threshold and present their online professional persona. Academics, as stakeholders of universities, have unfulfilled needs and expectations that, without attention, could lead to poor internal relationships, attrition, and reputational damage for the employing institution. At present there are a series of reactive approaches, where "short-term defensive reactions" (Porter and Kramer 82) have been reported (Horwedel; Thomason; Thompson; Gruzd, Staves and Wilk). Social media policies are currently designed to protect institutions (Liebler and Chaney), but more should be done to protect the individual academic. Universities could seize this opportunity to develop a proactive approach. This would provide institutions with a deeper understanding of how to tackle this emerging issue. Investment in managing this issue could aid in reducing reputational risk (Fombrun, Gardberg and Barnett) and assert universities as leaders in social responsibility best practice (Torrado, Bonilla and Clarke; Vallaeys; Wigmore-Álvarez and RuizLozano).

Currently, universities invest in some professional development that caters to the technical needs of its employees: presentations and seminars reinforce the importance of developing an online professional persona to reaffirm one's place in academia, and technical workshops prepare academics with skills to use new media. Mandatory training ensures academics are aware of social media policies and ethical communication. Consideration, however, should extend to support an academic's personal choice as to whether they are 
willing, or feel able, to connect with extended audiences through social media. If the creation and maintenance of professional personas becomes obligatory, institutions must invest in training and support that extends well beyond technical skills, and adjust workloads to embrace the ever-increasing time it takes for training and interacting online.

First, if universities are to address this issue, they must assign value to online professional personas. The time and energy it takes to maintain and monitor social media can be alleviated with more time and resources dedicated to this specific task. Social media monitoring, already conducted at institutional level, needs to expand and look beyond the reputational protection of the university and consider the individual. Second, professional development should become multi-faceted. Training in representational and presentational media should be provided regularly for all academics and not limited to a few high-profile academics that are perceived to have a higher likelihood of media interaction. Professional development should also consider the personality and well-being of the academic. Universities should take account of an individual's ability to manage this level of exposure by, a) helping the individual decide on the level of online engagement, b) helping the individual understand and identify the associated risks and, c) guiding individuals through issue management when problems arise. Reputation management is an ongoing task and, at times, may require an immediate and considered response to an emerging issue. In the cluttered, time-poor environment academics are working within, more assistance is required in managing such situations. From an emotional standpoint, timely pastoral care should also be extended to all staff requiring assistance.

To effectively manage the issues that have emerged from the constantly evolving academic landscape, key recommendations have been proposed. This paper has identified the implicit expectation that academics will develop, maintain, and monitor their professional persona as an additional task in an already over-crowded job description. Overall, the two core aspects that should be considered include, 1) work-load or time allocation to achieve this task, and 2) acknowledgement that not all academics have the ability to cope with this form of communication or the handling of criticism.

\section{CONCLUSION}

Traditionally, it was the more prominent "public intellectuals" that were visible to external audiences. It could be argued that their experience suitably equips them with the capacity to manage discourse with multiple audiences and cope with any potential criticism. Yet a proliferation of social media has presented a host of benefits for both emerging and established academics, and this has created opportunities and obligations for individuals to not only engage in public discourse, but to shape the presentation of their professional self through these media. Yet the very nature of enhanced visibility and immediacy can lead to irretrievable professional faux pas, errors, and experiences where internal policies cannot (or will not) protect an academic. Within an academic institution, all members of the community are expected to comply with policy and procedure surrounding the type of content deemed appropriate and acceptable when communicating with other members, yet once the academic engages in discourse external to their institution, they potentially become more vulnerable to negative exposure. More support should be offered to manage individual reputations in the public sphere.

Encouraging academics to present a professional persona to reach internal and external audiences is a valid marketing decision for both the academic and the employing institution. However, institutions must consider the variance in personalities, motives, and aspirations of the individual needs. There are extreme variations as to how individuals cope with public condemnation or even minor criticism. Warning signs or triggers are being felt among academics globally; significant pressures are impacting work-life balance and causing associated stress (Kinman and Wray). Universities that seek to leverage credibility or 
reputational gain from the reputational capital available from professional personas need to not only be aware of their social responsibility, but also proactively manage this evolving issue. If an institution seeks to fulfil the totality of its mission, which includes a contribution "to the struggle for justice, take up a level of social responsibility...and be vocal about the issues of our times" (Dorothy Smith 254), then improvements in social responsibility and issue management for internal stakeholders should be a priority.

\section{WORKS CITED}

Atherton, Cassandra. "Wise Guys: The Changing Role Of The Public Intellectual." 2013 Public Intellectuals Conference. Cambridge MA: Harvard Public Intellectual Committee, 2013. 16. Web. 20 Nov. 2014.

Barbour, Kim and P. David Marshall. "The academic online: Constructing persona through World Wide Web." First Monday 17.9 (2012). Web. 31 Aug. 2015.

Barbour, Kim, P. David Marshall and Chris Moore. "Persona to Persona Studies." M/C Journal 17.3 (2014): n. pag. Web. 8 Feb. 2015.

Barker, Derek. "The scholarship of engagement: A taxonomy of five emerging practices." Journal of Higher Education Outreach and Engagement 9. 2 (2004): 123 -137. Web. 8 Feb. 2015.

Björk, Bo-Christer and David Solomon. "The publishing delay in scholarly peer-reviewed journals." Journal of Informetrics 7.4 (2013): 914-923. Web. 12 Mar. 2015.

The BMJ. Peer review Process. 2015. Web. 10 Sept. 2015.

Boyer, Ernest L. Scholarship reconsidered: The priorities of the professoriate. Princeton, N.J.: Carnegie Foundation for the Advancement of Teaching. 1990. Web. 12 Mar. 2015.

The Conversation. Who we are. 2015. Web. 17 Sept. 2015.

Chapman, Simon. "Why I block trolls on Twitter." The Conversation, 12 Jan. 2015. Web. 10 Apr. 2015.

Fombrun, Charles. J., Naomi. A. Gardberg and Michael, L. Barnett. "Opportunity platforms and safety nets: Corporate citizenship and reputational risk." Business and Society Review 105.1 (2000): 85-106. Web. 15 Aug. 2015.

Gruzd, Anatoliy, Kathleen Staves and Amanda Wilk. "Connected scholars: Examining the role of social media in research practices of faculty using the UTAUT model." Computers in Human Behavior 28.6 (2012): 2340-2350. Web. 12 Mar. 2015.

Horwedel, Dina. M. “Blogging rights.” Diverse Issues in Higher Education 23.2 (2006): 28-31. Web. 12 Mar. 2015.

Kinman, Gail and Siobhan Wray. Higher Stress. A survey of stress and well-being among staff in higher education. University and College Union, 2013. Web. 12 Mar. 2015.

Liebler, Raizel and Keidra Chaney. "Here we are now, entertain us: Defining the line between personal and professional context on social media." Pace Law Review 35.1 (2014): 398 57. Web. 12 Sept. 2015.

Lightman, Alan. "The Role of the Public Intellectual." MIT Communications forum n.d. Web. 12 Mar. 2015.

Lupton, Deborah. "Feeling Better Connected: Academics' Use of Social Media." Canberra: News \& Media Research Centre, University of Canberra. 2014. Web. 8 Feb. 2015.

Marshall, P. David. "Persona studies: Mapping the proliferation of the public self." Journalism: theory, practice and criticism 15. 2 (2014): 153-170. Web. 8 Feb. 2015.

---."Personifying agency: The public-persona-place-issue continuum." Celebrity Studies 3. 4 (2013): 369-371. Web. 8 Feb. 2015.

Matrix, Sidneyeve. "Challenges, Opportunities, and New Expectations." Academic Matters, OCUFA's Journal of Higher Education May (2012) Web. 12 Aug. 2015.

Pennington, Gus and Brenda Smith. "Career-long competence: Unattainable ideal or professional requirement?" The Effective Academic: A handbook for enhanced academic practice. Eds 
Heather Fry, Steve Ketteridge and Stephanie Marshall. London: Kogan Page , 2002. 254 271. Web. 15 Aug. 2015.

Porter, Michael. E and Mark, K. Kramer. "Strategy and society: the competitive advantage of corporate philanthropy." Harvard Business Review 84.12 (2006): 78-92. Web. 15 Aug. 2015.

"Public intellectual." Collins Dictionary. 2015. Web. 10 Apr. 2015.

Reinhardt, Wolfgang, Martin Ebner, Gunter Beham and Cristina Costa. "How people are using Twitter during conferences." Draft Version - Originally published in: Creativity and Innovation Competencies on the Web. Eds. V. Hornung-Prähauser and M. Luckmann. Proceeding of 5. EduMedia conference, Salzburg, 2009: 145-156, Web. 10 Apr. 2015.

Rowe, John. "Student use of social media: when should the university intervene?" Journal of Higher Education Policy and Management 36.3 (2014): 241-256. Web. 10 April 2015.

Smith, David, K. "Academic Use of Twitter." Storify. 2013. Web. 8 Feb. 2015.

Smith, Dorothy. "On the Production Line? Academics in Modernized Universities." Advancing Knowledge in Higher Education: Universities in Turbulent Times. Ed. Tanya Fitzgerald. IGI Global, 2014. 254 - 264. Web. 15 Aug. 2015.

Thomason, Andy. "U. of Illinois Board Votes Down Salaita Appointment." The Chronicle of Higher Education. 11 Sept. 2014. Web. 8 Feb. 2015.

Thompson, Janna. "To tweet or not to tweet: academic freedom and social media." The Conversation 14 Oct. 2014. Web. 10 April 2015.

Torrado, Nellie, Daniel Bonilla and Linda Clarke. "Establishing a Theoretical Framework for University Social Responsibility: Review and Synthesis." The Latin American Council of Management School - Cladea 2012, Poster Session 2012, Lima, Peru, 22 to 24 October 2012. Web. 15 Aug. 2015.

Vallaeys, François. "Responsabilidad Social Universitaria." Programa para la Formación en Humanidades. D.R.(C) Tecnológico de Monterrey, Eugenio Garza Sada 2501, Col. Tecnológico, Monterrey, N.L. Mexico, 2007. 1-11. Web. 15 Aug. 2015.

Veletsianos, George. "Higher education scholars' participation and practices on Twitter." Journal of Computer Assisted Learning 28. 4 (2012): 336-349. Web. 8 Feb. 2015.

Weller, Jacolyn. "From Professional Expert to Novice Academic: Challenges and Complexities." Advancing Knowledge in Higher Education: Universities in Turbulent Times. Ed. Tanya Fitzgerald. IGI Global, 2014. 205 - 217. Web. 15 Aug. 2015.

Wigmore-Álvarez, Amber and Mercedes Ruiz-Lozano. "University Social Responsibility (USR) in the Global Context: An Overview of Literature." Business and Professional Ethics Journal 31.3-4 (2012): 475-498. Web. 8 Feb. 2015.

Sharyn McDonald is a Lecturer in the School of Communication \& Creative Arts at Deakin University in Melbourne. Her research focuses on social responsibility and issue management. 